Artigos 


\title{
A Google, o sistema de media e a agregação de informação*
}

\author{
Francisco Rui Cádima**
}

\section{Resumo}

A complexidade do modelo de convergência entre os media tradicionais e os novos media passa por um tempo de provação em torno do confronto que se tem verificado entre a Google e os editores de imprensa. A proposta é dirimir algumas questões que têm sido fracturantes para o actual modelo de migração para o digital, a saber: economia interconectada versus sistema tradicional de propriedade intelectual; sistemas de intermediação do acesso à informação (motores, agregadores, social media) versus sites de notícias dos media tradicional. A solução que se venha a encontrar para este contencioso poderá, no entanto, não resolver uma outra questão que não é de menor relevância e que integra o dispositivo técnico e algorítmico dos novos intermediários digitais: o condicionamento da matéria noticiosa e, portanto, do pluralismo e diversidade da informação.

Palavras chave: Media. Informação. Convergência. Agregação de notícias. Intermediários digitais.

\section{Google, media system and news aggregation Abstract}

The complexity of the convergence model between traditional media and new media passes through a time of testing around the confrontation that has been observed between Google and the publishers of the press. Our goal is to resolve some issues that have been divisive for the current model of migration to digi-

\footnotetext{
* Conserva-se o português de Portugal.

** Professor Catedrático do Departamento de Ciências da Comunicação (DCC) da Faculdade de Ciências Sociais e Humanas (FCSH) da Universidade Nova de Lisboa, Lisboa, Portugal. É ainda Coordenador Executivo do mesmo departamento e também Coordenador do Mestrado em Novos Media e Práticas Web (DCC-FCSH). Vice-presidente do CIMJ - Centro de Investigação Media e Jornalismo. Doutor em Ciências da Comunicação. E-mail: frcadima@fcsh.unl.pt
} 
tal, namely: interconnected economy versus traditional system of intellectual property; intermediation systems of access to information (engines, aggregators, social media) versus websites of traditional media. The solution that will be found for this litigation, probably does not resolve another issue which is of no less importance since it integrates the technical and algorithmic device of the new digital intermediaries: the conditioning of the news and therefore pluralism and diversity of information.

Keywords: Media. News. Convergence. News aggregation. Digital intermediaries.

\section{Google, el sistema de Medios de Comunicación y la agregación de información}

\section{Resumen}

La complejidad del modelo de convergencia entre los medios tradicionales y los nuevos medios está pasando por un tiempo de prueba en torno a la confrontación que se ha observado entre Google y los editores de la prensa. Nuestra propuesta es resolver algunas cuestiones que han sido fracturantes para el modelo actual de la migración a la tecnología digital, es decir: economía interconectada versus sistema tradicional de propiedad intelectual; sistemas de intermediación de acceso a la información (motores, agregadores, redes sociales) versus websites de medios de comunicación tradicionales. La solución que podrán encontrar para este litigio, sin embargo, no resuelve otro problema que no es de menor importancia y que integra el dispositivo técnico y algorítmico de los nuevos intermediarios digitales: el acondicionamiento de la noticia y por lo tanto el pluralismo y la diversidad de información.

Palabras clave: Medios de Comunicación. Noticias. Convergencia. Agregación de noticias. Intermediarios digitales.

"Em lugar de celebrar o mítico nirvana da desintermediação, deveríamos estudar as caixas pretas dos algoritmos de spam e dos bots de propaganda"

\section{Introdução}

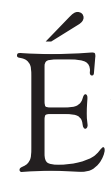

um facto que a convergência media/new media tem sido, basicamente desde meados dos anos 90, algo que se tem configurado em pouco mais do que uma aproximação frustrada, tendo gerado muito poucos sinais de conciliação ou de remediação entre os sistemas de media tradicionais e as grandes plataformas 
emergentes da Net. O que significa que, deste ponto de vista, estamos perante uma dificuldade intrínseca de ambos os sistemas em coincidirem e optimizarem os seus conhecimentos mútuos, o seu know-how, no novo paradigma comunicacional, potenciando e criando sinergias, novas economias de escala, sobretudo face às hesitações e ao declínio evidente do primeiro dos sistemas, tradicionalmente referido como o "quarto poder".

Etpour cause... Quer dizer, nessa dualidade está toda uma diferença programática e estratégica, nomeadamente aquela que separa a construção de uma opinião pública muito sintonizada com o discurso dos media tradicionais e dos seus líderes de opinião, de um novo campo comunicacional que não somente vem colocar em crise a "velha" indústria dos media como também a sua própria "expressão" jornalística, tantas vezes fortemente dependente dos mitos e interesses do tempo e agora cada vez mais diluída numa massa de informação que se auto-reproduz sobre a arquitectura matricial da rede, a cultura colaborativa, dialógica, interactiva, e a progressiva autonomização da esfera pública participativa da sociedade em rede. Paradoxalmente, tal situação sucede à imagem do próprio registro social, das suas ligações e interacções múltiplas e do seu diagrama complexo de permutações entre os diferentes indivíduos.

\section{Convergência/divergência}

Verificou-se, de certa maneira, um princípio de ruptura nesta continuada oposição convergência/divergência quando os editores de imprensa europeus começaram a questionar a legitimidade da Google para utilizar os conteúdos online dos media tradicionais no seu sistema de agregação de informação, designadamente utilizando o seu poderoso motor de busca para indexar notícias de terceiros na aplicação Google News. Veremos, mais à frente, de forma um pouco mais detalhada, o histórico deste confronto e os seus primeiros resultados. Importa agora, sobretudo, equacionar o contexto em que evoluiu essa vincada oposição entre o sistema de media e as plataformas emergentes na rede. 
Mas é evidente que entre a indústria de media e as plataformas Web há algo mais que as divide - e que paradoxalmente as pode unir -, mesmo continuando em campos opostos. Por exemplo, o factor económico, ou melhor, o novo princípio da economia digital, muito assente na lógica do capital social em rede ou do capital social virtual. Os novos modelos de interacção vêm aprofundar dinâmicas outrora impossíveis na era analógica, sobretudo no plano da colaboração e cooperação, tendo por objectivo a criação de vantagens mútuas de tipo comercial, mas também, por exemplo, a mediação de solidariedades, por meio de organizações da esfera não governamental ou mesmo de associações de cidadãos comuns.

Das redes de poder passamos assim ao poder das redes de interacção virtual, de natureza informal. Interactividade, partilha de informação, trabalho cooperativo, economia virtual, é sobre esta estrutura das redes que se reproduzem os novos fluxos de informação da economia interconectada, na expressão de Yochai Benkler, na sua muito citada obra The Wealth of Networks (2006). De facto, uma das especificidades da economia interconectada é justamente não ter barreiras à entrada, consagrar novas dinâmicas no plano da liberdade dos cidadãos e na partilha de informação entre indivíduos e comunidades.

Transposta para a economia digital, esta questão é vista por Benkler como uma nova centralidade a explorar, face aos mercados clássicos e ao modelo tradicional de organização social. Por exemplo, a propriedade intelectual - na perspectiva daquilo que é "comum" ou do domínio público -, evolui para uma economia política da produção colaborativa e depeerproduction colectiva, sendo que a partir de um certo nível da partilha e de produção social participativa e de interacção nas redes entre produsers, o próprio conceito de autoria aparece diluído ou adquire um estatuto de autoria colectiva.

Por meio deste modelo aberto de partilha entre pares, de consumo horizontal gratuito, de imediatismo da troca e da circulação dos conteúdos, estamos já a aproximar-nos do conceito de mediactivismo, que considera sobretudo o modo de subverter as bases da indústria cultural e da Comunicação como uma espécie de alternativa ao capitalismo ou ao neoliberalismo. Esta é já uma forma 
radicalizada de pensar o novo paradigmada cultura participativa e colaborativa (CÁDIMA, 2011) com base na lógica da desintermediação e sem hierarquias, o que, no limite, poderia querer significar a própria anulação de velhas estruturas de intermediação como a escola, o editor, a gestão do conhecimento e da informação, ou mesmo o sistema político-partidário das democracias tradicionais.

No entanto, à crise do primeiro campo de mediação industrial respondem agora pulsões múltiplas, fluxos e redes que se organizam e reproduzem, remediam e interagem numa dimensão matricial complexa e aberta, mas que só por si não garantem uma desintermediação, sobretudo técnica, com ganhos qualitativos, cognitivos e de conhecimento assegurados junto do utilizador final, o qual está agora num processo mais individualizado e autónomo de consumo da informação.

O facto é que a nova complexidade, o processo de mediação, exige novas literacias que não estavam ainda consolidadas no estádio imediatamente anterior, ou mesmo no processo de migração para o digital. O exemplo do motor de busca é claro sobre essa matéria: reorganiza e indexa preferencialmente a informação em função da sua maior atractividade e não em função da sua qualidade intrínseca e do eventual aprofundamento das matérias dos seus próprios conteúdos. Repare-se que motores de busca e agregadores acabam por ceder ao modelo da chamada "googlearchy" como Matthew Hindman (2006) lhe chamou, isto é, uma estrutura dominada por modelos de busca submetidos à lógica das audiências, dos clicks e das pageviews, mas que não permite a diversidade de acesso aos conteúdos e sobretudo a conteúdos qualitativamente diferenciados.

\section{Remediação/intermediação}

Nos sistemas de novos media entramos, num primeiro momento, numa dimensão reconstitutiva a que Jay David Bolter e Richard Grusin (1999) chamaram o plano da remediação, na encruzilhada entre as tecnologias do analógico e do digital, isto é, no qual a não-linearidade e o computacional vêm perturbar a 
narrativa mediática clássica e o velho dispositivo de mediação. Hibridez, ubiquidade e imersão são novos dados da experiência comunicacional, instituem-se como processo de remediação, e nele, também, ainda num primeiro tempo, a própria lógica de desintermediação. Assim, de facto, estas características marcam a emergência da experiência mediada pelo computador e a nova era dos media digitais.

Uma das ideias que marcaram este processo foi a de que os intermediários tradicionais estariam condenados à partida no novo ambiente digital. Era essa a percepção geral. Jeff Jarvis corrobora essa interpretação no seu livro sobre a Google (2010): "Para todos os intermediários, o relógio não pára e a questão do valor ganha mais peso. De cada vez que o Google cria uma ligação directa, diminui o valor de um intermediário" (2010, p.90). De facto, para Jarvis, aquilo a que ele chamou o mercado aberto da Internet iria tendencialmente anular os mercados ineficientes, tradicionais, do imobiliário à imprensa, das comunicações à saúde: "A Google não é a sua concorrência. A Google é a arma que os seus concorrentes empunham" (2010, p.94). Jarvis não reconhece, no entanto, que ao definir a Google como a alavanca de uma nova economia, ou a Amazon, ou o eBay, o Skype ou a Craiglist, definindo o "gratuito" como um mercado de desintermediação mais eficiente, está, no fundo, a encontrar novos intermediários onde antes estavam as empresas e os mercados da era pós-industrial.

Sucede assim que, ainda em pleno processo de migração e de remediação, estamos já perante, cada vez mais, a inversão do próprio princípio da desintermediação. Questão que se tem vindo a verificar ao longo dos anos mais recentes, de forma consistente, sobretudo no contexto da progressiva radicação do digital. A verdade é que à medida que as grandes estruturas e plataformas digitais se vão consolidando, o espaço da desintermediação fica cada vez mais reduzido e aparenta estar cada vez mais "localizado".

Essa é também a perspectiva de Evgeny Morozov, que vem chamar a atenção para este problema no seu texto "Na vida digital, cada vez mais intermediários". Neste trabalho publicado na Folha Online (2012), Morozov começa por reconhecer que a 
desintermediação costumava ser "louvada como traço definidor da era digital", o que pressuporia que em função do constante desenvolvimento tecnológico, "os intermediários de toda ordem estariam supostamente a caminho da extinção”. Mas não. Efectivamente parece estar a suceder e a consolidar-se um movimento contrário. Morozov fala então de "hiperintermediação" e não do seu oposto. Essa será porventura, agora, a tendência mais óbvia. Veja-se o exemplo que Morozov dá, de um blogger que inicia agora a sua actividade, sendo certo que ele hoje tem sofisticadas instâncias de intermediação que não existiam há alguns anos:

Uma pessoa que crie um blog em 2012 provavelmente vai terminar em uma plataforma comercial como o Tumblr ou o WordPress, e todos os comentários do blog serão administrados por meio de um provedor terceirizado como a Disqus. E os intermediários não ficam por aí: a Disqus coopera com uma empresa chamada Impermium, que utiliza diversos sistemas de aprendizado mecânico para determinar se os comentários postados são ou não spam [...] (MOROZOV, 2012)․․

De facto, sistemas mais complexos do ambiente Web 3.0, com especificações semânticas, estão hoje presentes na rede de um modo geral, garantindo aos proprietários de sites e plataformas um controlo de todo o tipo de conteúdo nocivo, desde o spam ao phishing, passando pelo bloqueio de linguagem menos própria ou mesmo pelo controlo de simples caixas de comentários.

Chama-se a isto a moderação automatizada de conteúdo. E é óbvio que na área política, designadamente nos países que têm já um longo contencioso com a liberdade na internet, estes sistemas de controlo têm ajudado à censura das opiniões dissidentes. Mas o mais preocupante é a utilização destas armas com sistemas informacionais que potenciam a sua eficácia no plano da localização geográfica, como o Spatial Big Data: "Por que não bloquear os comentários, vídeos e fotos subidos por usuários localizados,

${ }^{1}$ MOROZOV, Evgeny. Na vida digital, cada vez mais intermediários. Folha de S.Paulo, São Paulo, 29 out. 2012. Disponível em: http://www1.folha.uol.com.br/ colunas/evgenymorozov/1175587-na-vida-digital-cada-vez-mais-intermediarios. shtml. Acesso em: 4 jan. 2013. 
digamos, na praça Tahrir ou outro local politicamente explosivo? (MOROZOV, 2012)".

E isto é ainda somente o princípio da utilização de dispositivos intermediários de controlo da internet. Informação e contra-informação por parte dos Estados, são algumas das áreas que mais utilizam ferramentas analíticas de big data e novas modalidades semânticas de controlo da Web, ou que vão ainda mais longe, criando "robots" que criam e gerem tópicos em debate nas redes sociais, distribuindo mensagens em massa, inflacionando acessos aos trending topics do Tweeter ou criando múltiplas identidades falsas para subverter os modelos padronizados de interacção na internet, como refere Morozov (2012) na mesma análise:

Todo esse investimento em bots talvez tenha funcionado para o Kremlin: nos protestos que se seguiram às contestadas eleições legislativas de dezembro de 2011, o Twitter estava repleto de contas falsas que tentavam soterrar os hashtagsmais populares com informações irrelevantes. Um estudo recente alega que das 48.646 contas de Twitter que participaram de discussões sobre as eleições russas contestadas, 25.860 - mais de metade! - eram bots, que postaram 440.793 tweets sobre o tema².

É assim um facto que a tendência do digital é para reforçar um complexo conjunto de mecanismos de controlo do virtual e não tanto para abrir permissões indiscriminadas e autonomizadas na Web: "a digitalização aumentará, e não reduzirá, o número de intermediários em nossa vida pública. Não há nada de inerentemente malévolo nesses intermediários, se recordamos que é preciso mantê-los sob controle" (MOROZOV, 2012). Voltamos assim ao ponto de partida, restando-nos reconhecer que não estamos sós, de facto. Estamos efectivamente rodeados de "intermediários digitais" que detêm sistemas complexos de reorganização da informação, claramente distintos e com capacidades infinitas face ao velho sistema mediático estruturado em pirâmide.

\footnotetext{
${ }^{2}$ MOROZOV, Evgeny. Na vida digital, cada vez mais intermediários. Folha de S.Paulo, São Paulo, 29 out. 2012. Disponível em: http://www1.folha.uol.com.br/ colunas/evgenymorozov/1175587-na-vida-digital-cada-vez-mais-intermediarios. shtml. Acesso em: 4 jan. 2013.
} 
O exemplo da China não deixa de ser revelador da forma como estas estruturas reconstroem o campo da Comunicação. Desde logo trata-se de um país "SICK", na irónica acepção de Jing Zhao, na sua conferência TED intitulada "Behind the Great Firewall of China”. Sick significa aqui Síria, Irã, China e Coreia do Norte, os quatro países não têm acesso ao Facebook... O facto é que à imagem da grande muralha, a China também tem um grande firewall, que é, afinal, a maior fronteira digital do mundo: "Não apenas defende o regime chinês do exterior, dos valores universais, mas também impede os chineses de aceder à Internet livre" (ZHAO, 2012), como refere o blogger na mesma conferência.

Assim, a Internet é, localmente, uma espécie de Chinanet. Serão já cerca de 600 milhões de utilizadores no início de 2013, mas divididos pelas seguintes plataformas - dado que as originais, norte-americanas, estão bloqueadas pelo governo: Baidu (clone do Google), Weibo (clone do Twitter), Renren (clone do Facebook) e o Youku e Tudou (clones do YouTube). "Bloquear e clonar", e manter os dados nos servidores de Pequim, é essa a política oficial.

Apesar de tudo, no caso chinês, há algo que trespassa as barreiras. Não poderia ser de outro modo, dado que se pensa existirem mais de 300 milhões de microblogues na China, sendo que os 140 caracteres chineses do Weibo mais do que triplicam, em texto corrido,o que podem fazer 140 caracteres no ocidente. Tornaram-se assim num instrumento de grande utilidade no plano da crítica política, sobretudo para a velha petição pública nascida na era imperial, que paradoxalmente ainda parece manter-se.

Estes exemplos não deixam de ser preocupantes. Até porque esta intermediação para o controlo da rede e dos utilizadores tem sido muito direccionada para facilitar a censura e os bloqueios da Net por parte de regimes autoritários. Curiosamente é Silicon Valley que aqui também está presente. De acordo com o Citizen Lab da Universidade de Toronto, empresas como a Blue Coat Systems, ou a Impermium, segundo Evgeny Morozov, têm sido referidas como fornecedoras de Estados com problemas de direitos humanos, de aplicações e programas que permitem filtrar, censurar e vigiar a rede. 


\section{Intermediários digitais}

O relatório de Robin Foster, que o New Reuters Institute for the Study of Journalism (RISJ) publicou na rede em Julho de 2012, vem alertar para as complexas dinâmicas cada vez mais centradas do lado dos chamados "intermediários digitais", as quais estão a ter efeitos preocupantes, desde logo, sobre o pluralismo no contexto do digital, nomeadamente no que concerne ao acesso à informação jornalística online.

Estes novos intermediários são, ao fim e ao cabo, as mais populares e as maiores plataformas da Internet, que são hoje também, claramente, as maiores empresas norte-americanas: Google, Facebook, Apple, Amazon, Yahoo. O seu posicionamento em matéria de informação aproxima-se, no fundo, da caracterização algo caricatural feita por Eli Pariser sobre os novos gatekeepers, ou guardiões da informação, não já os jornalistas, mas, doravante, cada vez mais os próprios algoritmos que estão na base informacional destas plataformas. É certo que o relatório de Robin Foster concede que, "os novos e poderosos intermediários [...] podem desempenhar um papel muito positivo no sentido de facilitar o acesso amplo e aberto ao conteúdo noticioso em geral [...]. Mas a verdade é que Foster logo conclui que "as decisões que essas plataformas tomam podem igualmente restringir ou controlar o acesso às notícias” (FOSTER, 2012, p.5).

Esta questão é tanto mais crítica quanto se verifica, a partir de novos dados conhecidos, que estes intermediários digitais, integrados fundamentalmente por agregadores de notícias, redes sociais, motores de busca e "appstores" - estão a dominar o acesso à informação. De que forma? Precisamente pelo facto de intermediarem esse acesso, fazendo passar por si a maioria do tráfego para a matéria informativa: "30 por cento dos usuários de notícias online usam motores de busca como uma das principais formas de aceder às notícias, 22 por cento utilizam os agregadores de notícias e 20 por cento usam os media sociais" (FOSTER, 2012, p.6).

Foster separa a categoria de intermediários digitais classificando-os em quatro formas diferentes de intermediação - agre- 
gadores de notícias (Yahoo), motores de busca (Google), media social (Facebook), e lojas digitais e dispositivos (Apple inc.). Divide depois estas quatro formas de intermediação em dois grupos distintos. $O$ primeiro é composto essencialmente pelos agregadores de notícias e afins (Yahoo, MSN, HuffingtonPost etc.), que devem ser tratados como se integrassem o sistema de media, isto no que respeita designadamente às questões do pluralismo, da concentração e da regulação. Os restantes - os motores de busca, redes sociais e lojas de aplicativos - não afectando directamente o campo das notícias, têm ainda assim um impacto sobre o pluralismo, quer pela indexação da informação, opiniões e comentários, influência nos modelos económicos, ou mesmo pela influência política que podem induzir.

Robin Foster alerta para a necessidade de haver sobre estas matérias necessidade de um controlo imprescindível destes intermediários digitais. Isto porque se trata de uma área que não tem enquadramento de regulação, nem se vislumbra sequer vontade política para actuar nessa matéria, apesar das ameaças potenciais que este efeito "plataforma" sugere, uma vez que a reorganização da informação que este modelo implementa é tendencialmente redutor do pluralismo da informação. Daí uma renovada importância na actividade de regulação e nas políticas públicas aplicadas sobretudo ao sector dos novos media, de forma a haver um controlo efectivo sobre as questões relativas ao pluralismo em ambiente digital.

Ora, é neste contexto que se verifica agora um novo confronto, que tem o seu início não propriamente num modelo de convergência e que tem vindo a dar sinais de ultrapassar a oposição analógico/digital para se constituir porventura num modelo de forte optimização do analógico - neste caso o sistema de media tradicional - pelo digital, com intervenção directa da Google. Muito embora tenham e existam ainda sinais contraditórios, consoante as experiências e o histórico nos vários países que estão a procurar dirimir o contencioso em matéria de direitos de autor e de agregação de conteúdos. Vejamos então o que tem sucedido nos principais mercados nos quais o problema se tem colocado. 


\section{Google versus Editores}

A questão central deste problema é colocada por vezes de forma algo maniqueísta, como se estivéssemos basicamente ou perante uma ameaça, ou perante uma oportunidade. Será certamente algo mais complexo. À partida não devemos menosprezar a importância dos grandes motores de busca e respectivos agregadores, e, nesse sentido, falamos, fundamentalmente, de uma oportunidade digamos industrial, mas é certo que outras consequências daí advirão, pelo que a ameaça faz também parte do diagnóstico. O fenómeno da agregação tem hoje, aliás, diversas plataformas especializadas inclusive para tablets e smartphones. Apesar disso não se vê grande proactividade nos sistemas de media nacionais, ou nos grupos de Comunicação, no sentido de, por exemplo, "localizarem" sistemas de agregação nos mercados nacionais, entre diversos grupos ou dentro de diferentes media do mesmo grupo de Comunicação, ou protocolarem com os agregadores soluções convenientes a ambos os operadores, ou ainda outras soluções com plataformas alternativas.

Há, claro, um risco, ao se pretender evitar o potencial da agregação assente nas melhores plataformas: hoje, os chamados intermediários digitais (motores, agregadores, social media etc.) tornaram-se poderosíssimos sistemas de intermediação do acesso à informação. Repare-se que o acesso a notícias online, hoje passa sobretudo por esses intermediários e não directamente pelos sites dos meios tradicionais. Se pensarmos que o acesso às notícias, na internet, se faz maioritariamente (72\%), como vimos, pelos motores de busca, agregadores de notícias e social media, poderemos estar perante aquilo a que se chama uma "ameaça", sobretudo pelo que isso pode significar em termos de condicionamento da matéria noticiosa e de pluralismo da informação, que é justamente no qual o problema poderá ter uma dimensão mais preocupante.

Num breve enquadramento da situação na Europa, poder-se-ia identificar uma tendência comum entre diversos Estados-membros, ou seja, nos principais mercados há uma posição que é de certo modo transversal e que procura obter o apoio da Comissão Europeia no sentido de confrontar a Google com a obrigação do 
pagamento de direitos aos editores cujos conteúdos são indexados pela Google.

Certo é que embora hajam actualmente na Europa, no início de 2013, diversas iniciativas no sentido de confrontar a Google com as suas práticas de agregação de informação de produtores de conteúdos dos diferentes Estados-membros, visualizam-se pontualmente alguns sinais que podem vir a ser extremamente construtivos na definição das estratégias próximas e futuras e respectivos modelos de negócio. Porém, não nos iludamos, há já, de facto, várias queixas apresentadas à Comissão Europeia por abuso de posição dominante da Google. Pelo seu lado, a empresa responde na mesma moeda e em caso de conflito põe a hipótese de suspender a indexação de artigos de imprensa à Google News, alegando que o seu sistema de agregação é gerador de tráfego muito significativo para os sites de origem, dado que, segundo os seus responsáveis, redirecciona cerca de quatro bilhões de cliques por mês para as páginas web dos editores de imprensa a nível global. Talvez, por isso, é citado o exemplo da Associated Press que em 2010 também saiu da GoogleNews, tendo-se arrependido e regressado passado algumas semanas...

Já em 2010 era bem claro que os editores de três das grandes nações europeias - Alemanha, França e Itália - estavam unidos quanto à exigência de direitos conexos ou outros em relação à Google. A imprensa noticiava então que os editores europeus procuravam o apoio dos seus governos para pôr em prática mecanismos de defesa dos seus interesses (FERRAN, 2012). Posição que se mantinha no início de 2013, quando a imprensa volta a referir que continua a ser intenção do governo alemão aprovar legislação, no primeiro trimestre do ano, para impor à Google o pagamento de uma percentagem das receitas de publicidade sobre conteúdos dos editores de imprensa indexados pelo motor de busca.

$\mathrm{Na}$ França, François Hollande recebeu inclusivamente o Presidente da Google, Eric Schmidt, em Outubro de 2012, tendo referido que poderá também por meio de legislação específica, tal como pretendem os alemães, obrigar a empresa a pagar aos editores de imprensa pela indexação de conteúdos no Google News. 
O governo francês tem vindo a negociar direitos conexos desde aí com a Google e com a imprensa, no sentido de encontrar um equilíbrio na partilha de valor entre os criadores de conteúdo e o motor de busca. Na ausência de acordo entre as duas partes, o governo avançaria com decisões legislativas ou fiscais contra os motores de busca e os agregadores de informação, de forma a encontrar novos suportes ao financiamento da imprensa - seria a introdução da "Taxa Google", como lhe chamava a imprensa francesa $^{3}$. Aliás, o próprio governo francês estudava, simultaneamente, a introdução de mecanismos de apoio aos editores de imprensa nos seus projectos de migração para o digital.

O facto é que na Bélgica, ainda em 2012, surgia um acordo entre editores de imprensa e a Google que poderá fazer história e servir de modelo, nomeadamente a outros países europeus que procuram obter direitos conexos dos agregadores de conteúdos. $\mathrm{O}$ conflito com os belgas começou logo em 2006, quando os principais jornais belgas decidiram retirar os seus conteúdos do agregador e levar a questão para os tribunais. Sucede que, no final de 2012, foi encontrada uma solução a contento dos editores, de forma a ser encontrado um novo modelo de negócio e assim poderem gerar receitas a partir da sua própria matéria jornalística.

Neste acordo, a Google tem inclusive uma contribuição prévia para compensar o período de ausência na Google News por parte dos editores. A imprensa belga não só regressava ao agregador, como deveria contar com a disponibilidade da Google na compra de espaço publicitário para os editores. Ou ainda da sua permissão de acesso a ferramentas do grupo de forma a optimizar a presença da imprensa na Web, para melhorar a sua performance, por exemplo por meio do Ad Exchange, ou do Google Wallet, ou de social media como o Google +, por meio do Youtube etc. Para a Google, o exemplo belga pretende sobretudo deixar claro que não

\footnotetext{
${ }^{3}$ Veja-se o artigo publicado no LesÉchos - " 'Taxe Google': Hollande confirme", 16.01.2013. http://www.lesechos.fr/entreprises-secteurs/tech-medias/ actu/0202502476618-taxe-google-hollande-confirme-une-disposition-legislative-ou-fiscale-si-les-negociations-avec-les-editeurs-echouent-529165.php\#comments. Acesso em: 18 de janeiro de 2013.
} 
foi criado um precedente de pagamento a editores pela agregação online dos seus conteúdos.

\section{Em Portugal}

Em Portugal, de há algum tempo a esta parte, o sector dos media impressos tem vindo a alertar para o facto de a Google obter receitas sobre conteúdos produzidos pelos meios de Comunicação portugueses online, sem que estes tenham qualquer contrapartida financeira por esse facto. Entretanto, no início de 2013, a Confederação Portuguesa dos Meios de Comunicação Social (CPMCS) veio anunciar a possibilidade de apresentar uma queixa na Autoridade da Concorrência contra a Google (PACHECO, 2012).

Numa intervenção na conferência "Motores de Busca - o seu a seu Dono", organizada pela CPMCS (Lisboa, 17.01.2013), Francisco Pinto Balsemão, presidente do European Publishers Council e do grupo Impresa, voltou a insistir no tema, referindo que "os criadores dos conteúdos agregados nada recebem, apesar da visualização de parte ou da totalidade de cada conteúdo ser a base de receita da Google". Assim, deveria haver lugar a uma intermediação de uma entidade gestora de direitos de autor, à qual seria paga uma taxa, do tipo que está pensado para a Lei da Cópia Privada que deverá estabelecer uma taxação a incluir no preço final de equipamentos com capacidade de gravação de ficheiros, dos computadores aos smartphones, passando por discos externos etc. Outra possibilidade é haver acordos de licenciamento que garantam uma percentagem sobre a publicidade, ou ainda o pagamento em função do número de pageviews. Por outro lado, torna-se necessária a intervenção assertiva do campo da regulação a nível nacional, europeu, e de um modo geral, no mercado global.

$\mathrm{Na}$ sequência da referida conferência, o Governo português vinha confirmar estar atento ao problema, indicando ir constituir um grupo de trabalho para pensar o problema e fazer recomendações no sentido de ser produzida legislação adequada em matéria de utilização de conteúdos por agregadores e motores de busca, sendo previsível que até meados de 2013 haja uma decisão. 
A questão, em Portugal, assume uma dimensão maior dada a situação muito crítica do mercado publicitário. A queda do investimento publicitário entre Outubro de 2011 e Outubro de 2012 foi a mais forte dos últimos anos, tendo registado globalmente uma perda de 67,7 milhões de euros (-18\%), com o meio televisão a perder 36,4 milhões de euros $(-19,3 \%)$, sendo que a imprensa foi justamente o sector mais afectado, tendo perdido 13,9 milhões de euros $(-23,9 \%)$.

\section{No Brasil}

No caso do Brasil, no final de 2010, foi assinado entre os editores de imprensa, por meio da Associação Nacional de Jornais (ANJ) e a Google, um Protocolo designado genericamente por "Uma Linha no Google News". Tratava-se, claramente, de fazer crescer os acessos e assim valorizar os conteúdos jornalísticos por meio daquela plataforma de agregação. Mas não somente isso, dado que havia suficiente abertura para estender esta experiência a outras plataformas idênticas. $\mathrm{O}$ facto de se tratar apenas de uma linha indexada, quando anteriormente eram três linhas, tinha a ver justamente com as expectativas de aumento dos acessos aos sites dos jornais. Esta experiência tinha um tempo curto de duração seis meses, após o que deveria ser feito um balanço.

A experiência não terá sido a melhor, segundo a ANJ, e a partir daí verifica-se um movimento concertado pela associação de imprensa no sentido de provocar uma saída generalizada dos jornais brasileiros do Google Notícias:

A recomendação da ANJ foi seguida em massa pelos 154 jornais que integram a associação e respondem por mais de $90 \%$ da circulação de jornais no Brasil. Google argumenta que não há necessidade de nenhum pagamento pelo uso das manchetes, porque esta prática beneficia os jornais ao enviar a seus sites um grande volume de usuários (FRAGA, 2012).

Em todo o caso, diga-se que diversos sites dos portais de imprensa continuavam a ser fontes do agregador. $\mathrm{O}$ facto é que feita uma análise sobre esta saída em massa, até pelas características do mercado online brasileiro, onde a Google News tem uma visibi- 
lidade ainda escassa, verificou-se apenas uma diminuição de 5\% do tráfego, pelo que foi entendido pelos editores que valia a pena perder esse tráfego "em prol de um movimento importante que defende os princípios dos nossos direitos autorais e nossas marcas". (FRAGA; MAZOTTE, 2012). Segundo esta análise do Knight Center, que cita o jornalista Carlos Castilho, "o rompimento [da ANJ com o Google] está na contramão de todas as mudanças produzidas pela economia e tecnologia digitais no processo de Comunicação jornalística" (CASTILHO, 2012). De facto, mais uma vez se comprova que há uma clara dificuldade por parte dos executivos do sector de media em integrar nas redacções as novas convergências com o digital e as suas plataformas emergentes. Isso seria natural no final dos anos 90 , na fase imediatamente anterior à "bolha dot.com". Mas entretanto passou mais de uma década e não só não se consolidou um novo modelo de negócio para os media tradicionais, como continuam a verificar-se diversíssimas resistências e condicionamentos na migração para o digital. ${ }^{4}$

\section{Notas finais}

Na tese supra citada, Ricardo Nunes identifica aquilo a que chama uma "falta de cultura digital na estrutura organizacional da empresa", nesta caso nas televisões públicas de Portugal e Espanha, "associada à falta de massa crítica a vários níveis: gestão, redactores, consumidores [...]" como explicação para os bloqueios que se mantêm desde os anos 90 do século passado.

Essa será certamente uma das causas do fenómeno de reduzida convergência no sector de media e mesmo de algum isolamento face às empresas de inovação tecnológica e de desenvolvimento de software e aplicações. $\mathrm{O}$ digital tem crescido com estas estruturas e empresas um pouco de costas voltadas, com a não integração da ideia de interactividade nos diferentes

\footnotetext{
${ }^{4}$ Veja-se, por exemplo, sobre esta matéria, a tese de doutoramento de Ricardo Nunes "Condicionantes do dispositivo mediático na formatação de conteúdos multimédia: análise do dispositivo online do serviço público de televisão em Portugal e Espanha”. FCSH-UNL, 2012.
} 
níveis da informação - da pré-produção à distribuição - de algum corporativismo castrador na profissão, e isso tem sido dramático para o campo da Comunicação jornalística que está a cair nalgum isolamento face à multiplicidade de "estímulos" informativos, feeds, social media etc., da rede.

À reduzida cultura digital, acresce uma frágil cultura jurídica neste novo contexto. Se é certo que em alguns quadros legislativos, como sucede no Brasil, a lei de direitos de autor não impede a reprodução de conteúdo jornalístico por outros veículos, já nalguns países europeus existe jurisprudência nessa matéria, pelo que a agregação de notícias pode efectivamente configurar um ilícito em matéria de direito de autor. Paralelamente, coloca-se a questão do modelo de negócio, que poderá ter um desenvolvimento relativamente rápido, tal como sucedeu já no caso da Bélgica. A solução belga poderia ser inclusive uma referência, para esta fase, para todos os outros países em contencioso com a Google. Mas mesmo que o não venha a ser, foi já uma importante vitória da convergência media/new media. Assim ela possa ser inspiradora para os próximos passos a dar.

\section{Referências}

BENKER, Yochai.The wealth of networks: how Social production transforms markets and freedom. New Haven: Yale University Press, 2006.

CÁDIMA, F. Rui. A televisão, o digital e a cultura participativa. Lisboa: MediaXXI, 2011.

CASTILHO, Carlos. Jornais vs. Google: a briga que ninguém ganha. Observatório da Imprensa - Código Aberto. 23 out. 2012. Disponível em: http:// www.observatoriodaimprensa.com.br/posts/view/jornais_x_google_uma_briga_onde_ninguem_ganha. Acesso em: 25 jan. 2013.

FERRAN, Benjamin. Presse: France, AllemagneetItalieuniescontre Google. Figaroonline, 25 out. 2012. Disponível em: http://www.lefigaro. fr/medias/2012/10/25/20004-20121025ARTFIG00528-presse-france-allemagne-et-italie-unis-contre-google.php. Acesso em: 12 jan. 2013.

FOSTER, Robin. News plurality in a digital world. Oxford: New Reuters Institute for the Study of Journalism/ RISJ, 2012. Disponível em: http://reuter- 
sinstitute.politics.ox.ac.uk/fileadmin/documents/Publications/Working_Papers/ News_Plurality_in_a_Digital_World.pdf. Acesso em: 18 nov. 2012.

FRAGA, Isabela. Jornais brasileiros abandonam em massa o serviço Google Notícias. Blog Jornalismo nas Américas. 18 out. 2012. Disponível em: http://knightcenter.utexas.edu/pt-br/blog/00-11786-jornais-brasileiros-abandonam-em-massa-o-servico-google-noticias. Acesso em: 25 jan. 2013.

FRAGA, Isabela; MAZOTTE, Natalia. Boicote ao Google News resultou em queda de apenas $5 \%$ do tráfego na web, afirmam jornais brasileiros. Blog Jornalismo nas Américas. 25 out. 2012. Disponível em: https://knightcenter. utexas.edu/pt-br/blog/00-11882-boicote-ao-google-news-resultou-em-queda-de-apenas-5-do-trafego-na-web-afirmam-jornais. Acesso em: 25 jan. 2013.

HINDMAN, Matthew. The myth of digital democracy. New Jersey: Princeton University Press, 2009.

JARVIS, Jeff. O que faria o Google?. Lisboa: GestãoPlus Edições, 2010.

MOROZOV, Evgeny. Na vida digital, cada vez mais intermediários. Folha de S.Paulo (tec online), São Paulo, 29 out.2012. Disponível em: http://www1. folha.uol.com.br/colunas/evgenymorozov/1175587-na-vida-digital-cada-vez-mais-intermediarios.shtml. Acesso em: 4 jan. 2013.

NUNES, Ricardo J. M. Condicionantes do dispositivo mediático na formatação de conteúdos multimédia: análise do dispositivo online do serviço público de televisão em Portugal e Espanha. 2011. Tese (Doutorado em Ciências da Comunicação) - Faculdade de Ciências Sociais e Humanas, Universidade Nova Lisboa - Run - Repositório UNL. Disponível em: http://run.unl.pt/ handle/10362/7346. Acesso em: 30 nov. 2012.

PACHECO, Filipe. Patrões dos media admitem apresentar queixa contra Google. Jornal de Negócios online, 17 jan. 2013. Disponível em: http://www. jornaldenegocios.pt/empresas/media/detalhe/patroes_dos_media_admitem apresentar_queixa_contra_google.html. Acesso em: 18 jan. $201 \overline{3}$.

PARISER, Eli. The filter bubble - what the internet is hidding from you. New York: the penguin press, 2011.

ZHAO, Jing (aka Michael Anti). Behind the Great Firewall of China (Ted Talk). Filmed in jun 2012. Posted jul 2012 TEDGlobal 2012. Disponível em: http://www.ted.com/talks/lang/en/michael_anti_behind_the_great_firewall_of_ china.html. Acesso em: 12 jan. 2013.

Recebido: 29/01/2013 Aceito: 05/04/2013 